\title{
Empathic Design: Understanding User Experience Through Schema Changes and Innovative Design
}

\author{
Shu-huei Wang \\ MingDao University, \\ Changhua,Taiwan
}

\author{
Shyh-huei Hwang, Ming-chyuan Ho \\ National Yunlin University of Science and Technology, \\ Yunlin, Taiwan
}

\begin{abstract}
As administration of blogs is one of the most popular activities on the Internet currently, topics related to blogs have also become a favorite subject in daily life. Questions like what ways can be used to show end-users' or designers' internal knowledge to find out their needs, what methods can be applied to analysis of the process, etc., have not been answered yet. Therefore, how to analyze the tacit knowledge and grasp the true demand of users is one of the major issues to be solved in empathic design. The purpose of this research is to examine the difference of whether the "comparison table of schema changes for users at three points of time" was taken into consideration or not in an empathic design brainstorming meeting. The tests consist of the experimental group and the control group. The former did not refer to the comparison table; however, the latter used it for discussion. The result indicates this comparison table helped the control group significantly in presenting an ultimate blog design of innovative ideas.
\end{abstract}

Keywords: empathic design, design methodology, schematic changes, user experience, innovative design

\section{Introduction}

Empathetic design is an emerging field in the topic of managing strategy and marketing investigation. Traditionally, marketing investigation incorporates quantitative research and questionnaires to present the research results in numeric. Empathetic design which employs the flied study originated from anthropology to investigate the daily life of research participants. Researchers personally have to observe and keep a record of the creative designing process for developing a product, service, or innovative concepts consumers need. Empathetic design was usually used in the early product development period or in the designing process to generate innovative concepts. Dorothy and Jeffrey (1997, p. 104) provided five steps of empathetic design and asked what ways can be used to show end-user's or designer's internal knowledge to find out their needs and what methods can be applied to analysis of the process. Such questions have not been answered to potentially critical customer needs. Therefore, the main problem to be solved of empathetic design is to analyze the users' inner knowledge and to realize their need. Therefore, how to analyze the tacit knowledge and grasp the true demand of users is one of the major issues to be solved in empathic design.

Shu-huei Wang, assistant professor, Department of Digital Design, MingDao University. 
For finding out the potential need of the users, there are two parts in this research. In the first part, the research interviewed bloggers about the issue of blog design for three times every five weeks. The qualitative research and narrative research were employed to interpret the process of the schema changes. There are four participants. The research lasted for three months. The results, based on the grounded theory and the comparison of the schema changes, were discussed and analyzed for further design of blogs (Wang, Chuang, Fang, \& Ho, 2008, pp. 197-208).

This research is a subsequent study for the second phase to verify and analyze the "comparison table of schema changes for users at three points of time"1 as the experimental variable. It was presumed that reference of the comparison table provided significant help to innovative design concepts on an early stage in an empathic design brainstorming meeting. The result reveals reference to the comparison table not only helped significantly, but also motivated innovative ideas for an ultimate blog design.

\section{Literature Review}

\section{Empathic Design}

Recently, it was proposed that empathy was the origin of cultures as well as a second social value. Human civilizations would be impossible without it (Rifykin, 2001). Empathy, a bridge for communication, establishes a common consensus even in different cultures. Just as Rifykin (2001) indicated that mankind is capable of understanding others and search for a common view through empathy. Empathy is a feeling that helps social trust grows. The so-called empathic sympathy depends on whether you can put others into your own imaginative space or not. It is one of the deepest emotions of human beings as well as the creator of cohering a close relationship and modesty among people (Rifykin, 2001). Empathic design uses cultures and imagination as the motive force for creation.

Dorothy and Jeffrey (1997), professors of Harvard Business School, presented their perspectives of empathic design (observed from the environmental conditions of the consumers themselves). They considered that sometimes consumers took the products and service offered for granted that they did not think of a new solution even when their real requirements were not met. They have noted that five steps are involved in empathic design, including: (1) customer observation; (2) data gathering through visual, auditory, and sensory cues; (3) analysis of data; (4) brainstorming; and (5) the development of prototypes of possible solutions (Dorothy \& Jeffrey, 1997, p. 104). These research methodologies can provide designers and researchers a few ways to observe and understand users. Also, asked what ways can be used to show end-user's or designer's internal knowledge to find out their needs, what methods can be applied to analysis of the process, etc.

Empathic design is based on empathy, which occurs in every phase of the design process. For instance, empathy is required when observing users and five empathic senses are exercised for data collection and analysis. Empathic methods are created by storyboard, storytelling, narrative matters and scenarios, and so on.

1 "The comparison table of schema changes at three points of time" is called the comparison table for short. 


\section{Schema Theory}

Piaget (1954) considered that adaptation can be divided as assimilation and accommodation. The process of accommodation was that an individual who assimilated or absorbed things based on its cognitive structure and schema. The process of accommodation required the change of an individual to accommodate outside world or environment ( $\mathrm{Su}$ et al., 1995). The concepts of assimilation and accommodation were the basis of the cognitive development. That is, the cognition developed based on assimilation and accommodation (Chang, Hsu, Cheng, Lei, \& Ksuo, 2004).

The basic assumption of schema provided by Adams and Collins (1979) was that the articles (oral or written articles) which were meaningless only provided listeners or readers a way to use their own knowledge and to construct meanings. The process involved the data directed and concept directed process. According to the cognitive development theory provided by Piaget (1954), the basic unit of cognitive structure was schema, which also represented a name of things and the principle to make a conclusion ( $\mathrm{Su}$ et al., 1995). Schema was the event, situation or well organized cognitive unit (Moates \& Schumacher, 1980). Fiske and Taylor (1991) pointed that schema was an important psychological mechanism when human beings processed a message. Schema was formed by human beings based on the understanding of an individual and the knowledge structure of former experience. The structure contained the related and inter-related concept of the individual. The origin, concept, function, and operation of schema were described. However, schema was a unique knowledge system and people received different information even when they read the same article and input.

\section{User Experience}

User experience is a term to test product satisfaction and use and usually applied to software or marketing testing. Norman (1999) described that there are product development to starts with users and their needs rather than with technology. Then, Kuniavsky, a founding partner at Adaptive Path, in his book Observing the User Experience (2003), considered it a comprehensive how-to reference to more than a dozen highly effective user research techniques. Rubinoff (2004) said: "The user experience is primarily made up of four factors: branding, usability, functionality, content". All four elements provide the basis for success. Paluch (2006) had been noted in his web "user experience is the characterization of what a user feels while using any product, this can extend from a car to a mobile phone to a magazine or a child's toy". It means how users feel about and describe the product or service after use. Recently, Reiss (2009) in his blog gave a definition of user experience: "User experience (UX) $=$ the sum of a series of interactions" (Reiss, 2009).

The expectation and need of the users matter the most when designing a new product. If no investigation about the expectation and need of the users is made before design, it goes without saying that the product might have poor selling or be unwanted when launching, which will be a nightmare for every company and designer. As a result, it is critically important to know the expectation and need of the users, before creating and marketing a new product in particular. Designers cannot rely on their own experience and knowledge merely. They may obtain more relevant information from the consumers in various ways. For example, designers can ask users to try a new product and give their opinions about it for reference. Users are like partners of designers, which is unprecedented. Such ways of data collection are user-centered design 
approaches. Frequently asked questions are like what does the user want, why does the user want this, what does the user expect, etc.

\section{Methodologies}

This exploratory research is a more effective way in determining correlations. The experimenters usually attempt to create an artificial situation to get necessary and specific information and assess the information obtained in a correct manner. There are different categories for experimentation methods. Laboratory experimentation and field experimentation are divided according to the features of experimental settings. The former refers to experiments conducted in an artificially arranged laboratory and the latter means experiments performed in a natural setting (Chou, 2002).

\section{Research Method}

For a clearer causality among variables, laboratory experimentation was adopted due to its optimum internal validity. Though the external validity of this approach is lower; however, the correlation between independent and dependent variables concerned in this research can be explored precisely through control of variables. The main purpose of this experiment is to verify if potential demands of customers and innovative ideas can be located more easily by referring to the comparison table of schema changes for users at three points of time (see Table 1). The independent variable is defined as the comparison table and the dependent variable means the result of with or without reference to the table. Dependent samples are included. Four participants joined a two-part experiment respectively. The first part is a brainstorming meeting without referring to the comparison table and the second part is a brainstorming meeting with the comparison table considered. The whole experimental process was recorded in five different ways, including videotaping, tape recording and picture taking from various angles by four video recorders in the observation room, and answers and plots provided by the participants themselves.

\section{Research Structure}

This research is a follow-up on the thesis titled Exploring Schema Changes for design blog. The same four respondents were interviewed at three points of time, $\mathrm{t} 1, \mathrm{t} 2$, and $\mathrm{t} 3$, separated by five weeks respectively. The process of schema changes perceived by the respondents was analyzed from the perspective of time. Two of the respondents have a design background and the other two do not. All four of them have experience of maintaining a blog for one to two years. Common views and personal ideas of four respondents at $\mathrm{t} 1, \mathrm{t} 2$, and $\mathrm{t} 3$ were analyzed, compared and presented in a table. Design issues and suggestions were provided based on the function, value, privacy, communication, and future development of blogs. Business-oriented values, future function, and privacy of blogs were also recommended.

Table 1 is the first stage study on tracking and analysis of potential demands of users with a research structure depicted as follows (see Figure 1).

Answers to what approach can be used to exactly analyze the potential needs of customers in empathic design are not completely clear yet. The objective of the experiment in this research is to probe the difference of whether the "comparison table of schema changes for users at three points of time" is referred to or not in an empathic design brainstorming meeting. Thus, whether tracking of schema changes perceived by blog users is 
helpful for the internal knowledge of end-users and how to discover demands of customers will be examined. The network commercialization feature provided by blog design on the brainstorming stage in empathic design is explored here. This research is the second phase of the whole project to examine the difference between referring to and not referring to the comparison table in a brainstorming meeting. The research structure is as follows (see Figure 2).

Table 1

Comparison Table of Schema Changes for Users at Three Points of Time

\begin{tabular}{|c|c|c|c|c|c|c|c|c|c|c|c|c|c|c|c|}
\hline Time & $\begin{array}{l}\text { The } \\
\text { functi } \\
\text { on of } \\
\text { blog }\end{array}$ & $\begin{array}{l}\text { Blog } \\
\text { web }\end{array}$ & $\begin{array}{l}\text { The } \\
\text { content } \\
\text { of blog }\end{array}$ & $\begin{array}{l}\text { The } \\
\text { experie } \\
\text { nce of } \\
\text { blog }\end{array}$ & \begin{tabular}{|l} 
The \\
Techno \\
f logy of \\
blog
\end{tabular} & $\begin{array}{l}\text { The } \\
\text { Disadva } \\
\text { ntage of } \\
\text { blog }\end{array}$ & $\begin{array}{l}\text { The } \\
\text { advant } \\
\text { age of } \\
\text { blog }\end{array}$ & $\begin{array}{l}\text { The } \\
\text { sharing } \\
\text { of blog }\end{array}$ & \begin{tabular}{|l} 
The \\
commun \\
ication \\
of blog
\end{tabular} & $\begin{array}{l}\text { The } \\
\text { Privac } \\
\text { y of } \\
\text { blog }\end{array}$ & \begin{tabular}{|l|} 
The \\
future \\
functio \\
n of \\
blog \\
\end{tabular} & \begin{tabular}{|l}
\multicolumn{1}{|c}{ The } \\
values \\
of \\
busines \\
s
\end{tabular} & $\begin{array}{l}\text { The } \\
\text { other } \\
\text { ways of } \\
\text { commun } \\
\text { ication }\end{array}$ & \begin{tabular}{|l|} 
Blog \\
$\mathrm{f}$ \\
softwa \\
re
\end{tabular} & $\begin{array}{l}\text { The } \\
\text { spendi } \\
\text { ng } \\
\text { of blog }\end{array}$ \\
\hline $\mathrm{t} 1$ & VI & $\mathrm{VI}$ & VI & $\mathrm{VI}$ & Ш & Ш & Ш & VI & VI & * & & & & & \\
\hline $\mathrm{t} 2$ & $\mathrm{VI}$ & & $\mathrm{VI}$ & Ш & & $\Pi$ & $\mathrm{VI}$ & VI & Ш & $\Pi$ & & & & & \\
\hline $\mathrm{t} 3$ & VI & $\mathrm{VI}$ & VI & Ш & & $\Pi$ & VI & VI & VI & & Ш & & & & \\
\hline
\end{tabular}

Notes. " Code-I: personal cognitive schema; code-П: the overlapping of two participants; code-Ш: the overlapping of three participants; and code-VI: the overlapping of four participants.
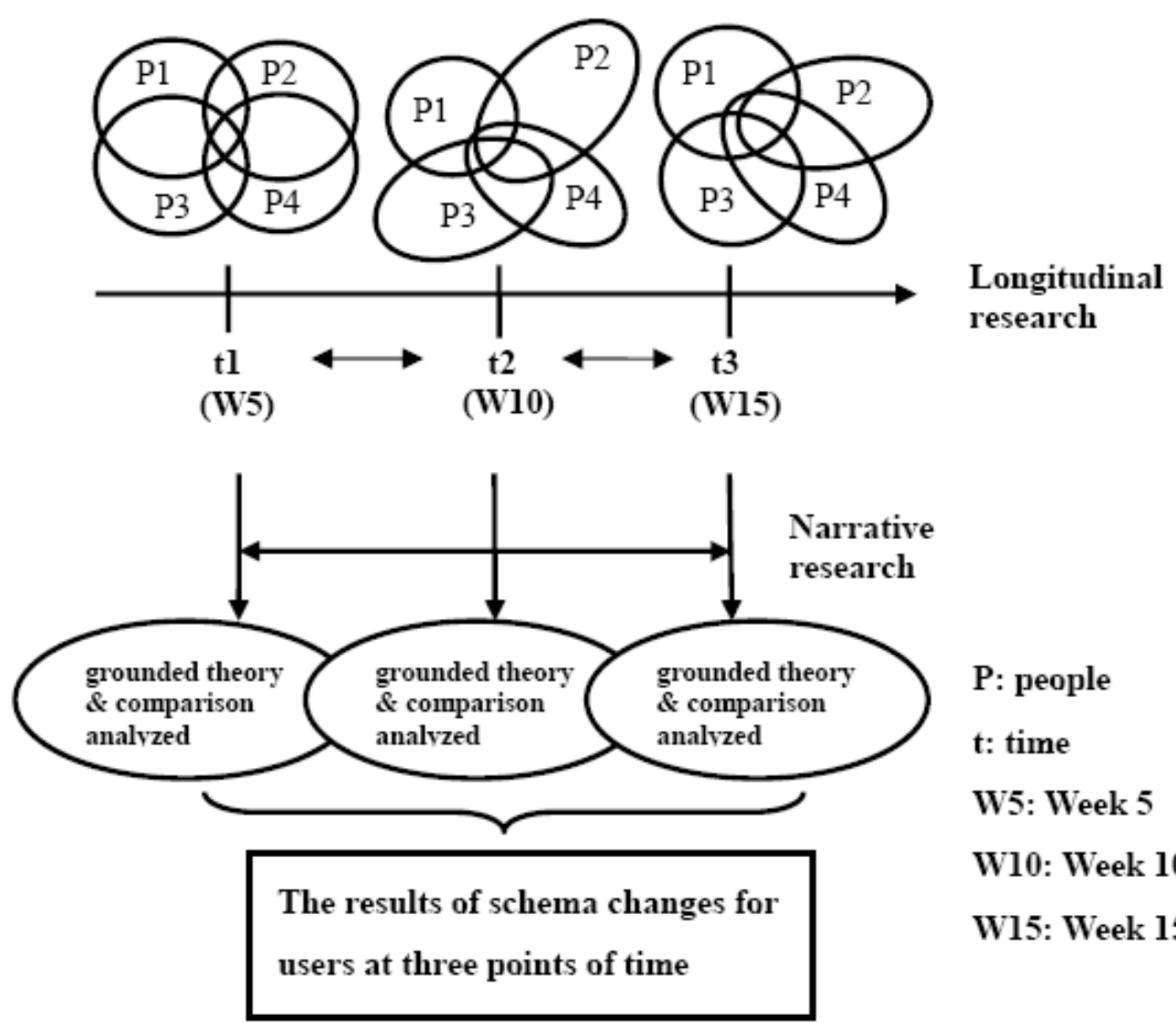
P: people
t: time

W5: Week 5

W10: Week 10

W15: Week 15

Figure 1. First phase research structure (mapped by this research). 


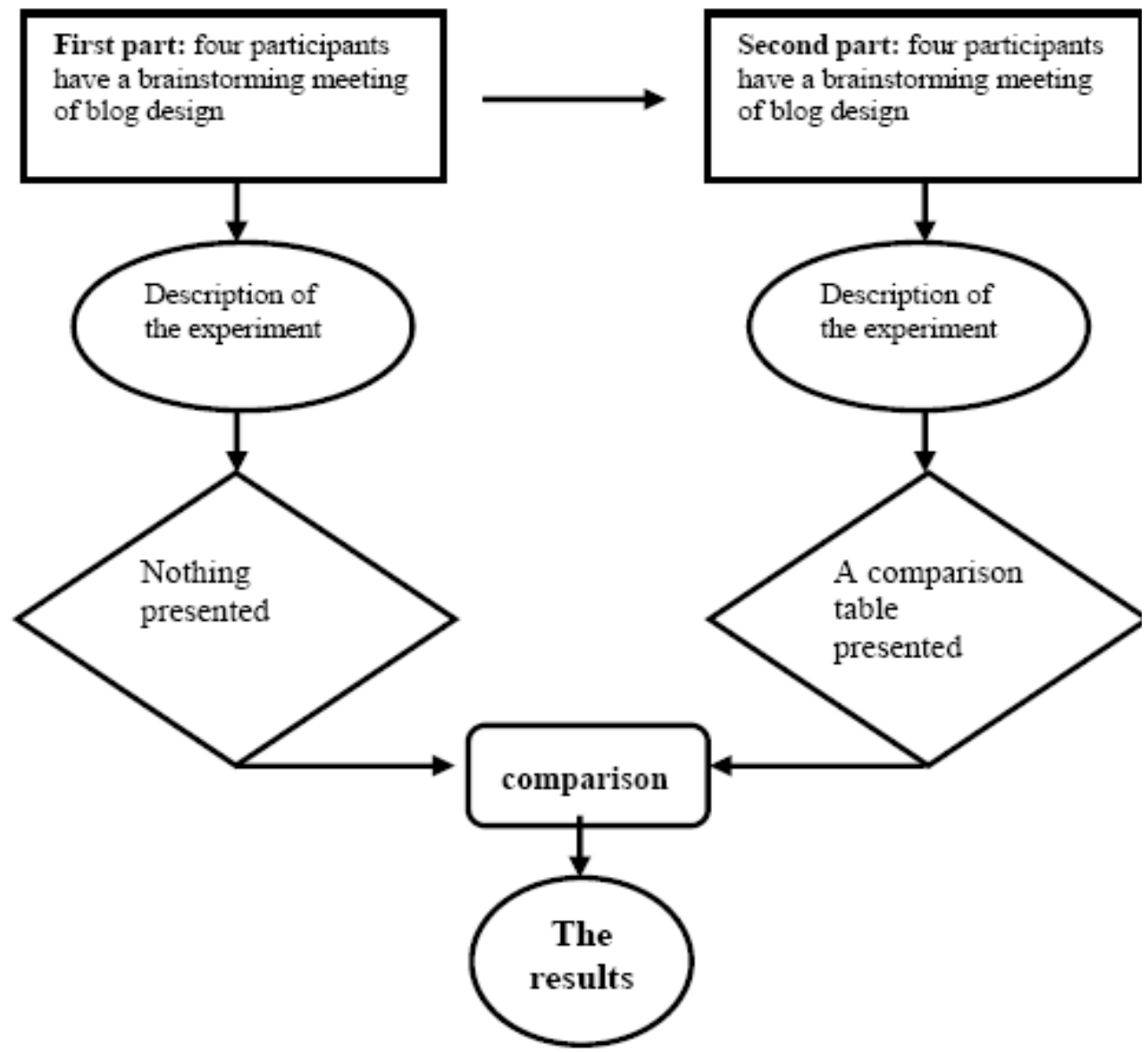

Figure 2. Second phase research structure (mapped by this research).

\section{Participants}

Purposive sampling was conducted in this qualitative research with dependent samples for an understanding of a causal relationship between these two parts. Two of the participants have a digital media design background and the other two have a visual communication design background. The major reason for purposeful sampling is, because all four of them have experience of design and blog use with three to five years of blog management (refer to the Table 2 for details).

Table 2

Basic Information of Participants

\begin{tabular}{|l|l|l|l|l|}
\hline Number & P1 & P2 & P3 & P4 \\
\hline Sex & Female & Female & Female & Female \\
\hline Grade & $\begin{array}{l}\text { Graduate student } \\
\text { grade }\end{array}$ & $\begin{array}{l}\text { Graduate student } \\
\text { grade }\end{array}$ & $\begin{array}{l}\text { Graduate student 2nd } \\
\text { grade }\end{array}$ & $\begin{array}{l}\text { Graduate student 2nd } \\
\text { grade }\end{array}$ \\
\hline Background & Digital media design & Digital media design & $\begin{array}{l}\text { Visual communication } \\
\text { design }\end{array}$ & $\begin{array}{l}\text { Visual communication } \\
\text { design }\end{array}$ \\
\hline Age & 24 & 23 & 27 & 27 \\
\hline Platform & Google & Fc2 & Wretch & Wretch/yahoo \\
\hline Blog experience & Three years & Five years & Three years & Five years \\
\hline Design experience & One year & Two years & Three years & Three years \\
\hline
\end{tabular}




\section{Data Collection}

Four participants attended the brainstorming meeting for blog design together and the whole meeting in the laboratory was divided into two stages. The researcher video taped, tape recorded, and took pictures during the whole process in addition to the answers and plots provided by participants themselves (see Figures 3-4).

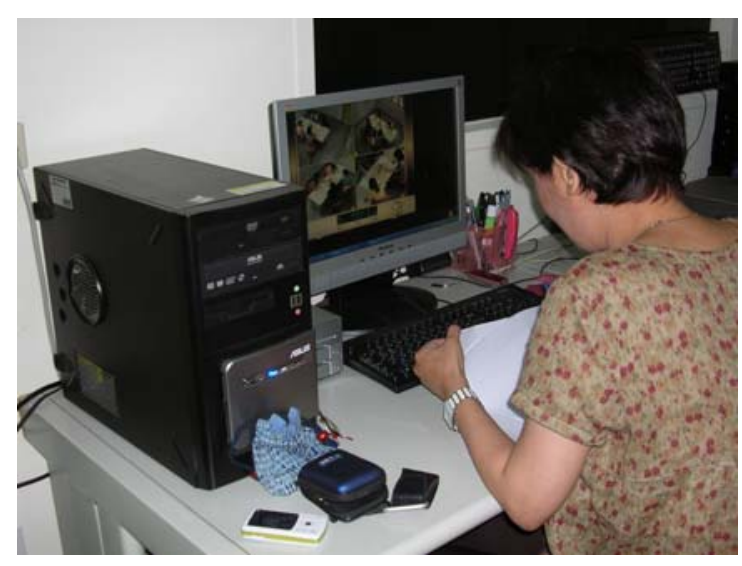

Figure 3. Computer records from four monitors.

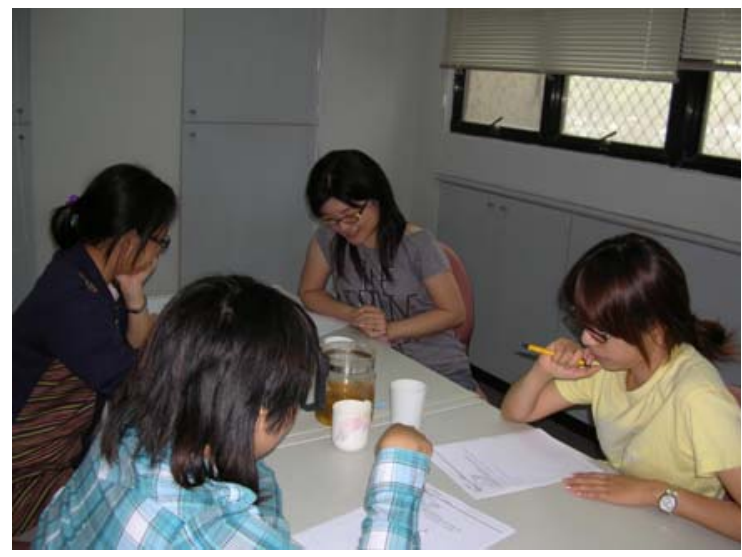

Figure 4. Four participants at brainstorming meeting.

\section{Results and Discussion}

Description of the experiment: (1) date: May 7, 2009; (2) time: 1:45-3:30 p.m.; and (3) place: Human Factors Engineering Lab., NYUST (National Yunlin University of Science and Technology). The blog design brainstorming meeting attended by four participants was divided into two parts described as follows. Questions for the first part experiment (without referring to the table) are: Q1 personal knowledge of blog; Q2 feelings of using blog; Q3 re-design a new blog; and Q4 brainstorming for blog design suggestions or design originality (opinions expressed by sketching). The duration of the first part experiment was from 13:45 to 14:15 separated by five minutes of explanation (13:45-13:50) and 25 minutes for brainstorming (13:50-14:15). Questions for the second part experiment (referring to the table) are: Q1 discussion of participants about the comparison table; Q2 creative thinking; Q3 sketching time; and Q4 discussion of sketches and determination of the final drawing (on the whiteboard). The duration of the second part experiment was from 14:35 to 15:30 separated by five minutes of explanation (14:35-14:40) and 50 minutes for brainstorming (14:40-15:30). 


\section{Results}

Limited to the space, only the contrast table of paper-based answers and the final blog design sketches are discussed here. Besides, tape recording results and comparison table of paper-based drawings are also contained (including Q4 of the first part and Q3 and Q4 of the second part). These results will be used for further analysis later. The experimental results are listed as follows (see Table 3).

Table 3

Contrast Table of Paper-Based Answers Provided by Participants

\begin{tabular}{|c|c|c|c|c|c|}
\hline & \multicolumn{3}{|c|}{ First part experiment (not referring to the comparison table) } & \multicolumn{2}{|c|}{$\begin{array}{l}\text { Second part experiment (referring to the comparison } \\
\text { table) }\end{array}$} \\
\hline NO. & $\begin{array}{l}\text { Q1: Knowledge of } \\
\text { blog }\end{array}$ & $\begin{array}{l}\text { Q2: Impression on } \\
\text { blog }\end{array}$ & Q3: Re-design & $\begin{array}{l}\text { Q1: Discuss the } \\
\text { comparison } \\
\text { table }\end{array}$ & Q2: Creative thinking \\
\hline P1 & $\begin{array}{l}\text { Public daily } \\
\text { record on the net, } \\
\text { a platform of } \\
\text { sharing and a } \\
\text { good tool for } \\
\text { information } \\
\text { exchange }\end{array}$ & $\begin{array}{l}\text { Advantages: not } \\
\text { many hardware and } \\
\text { software } \\
\text { requirements, only a } \\
\text { browser required } \\
\text { Disadvantages: no } \\
\text { privacy on blogs, } \\
\text { confusion of posting } \\
\text { articles }\end{array}$ & $\begin{array}{l}\text { Hand drawing and } \\
\text { animation features }\end{array}$ & \begin{tabular}{|l|} 
Features, \\
contents and \\
sharing of blogs
\end{tabular} & $\begin{array}{l}\text { Tape recording, a personal broadcasting } \\
\text { station, 3D screen, involvement of } \\
\text { situations }\end{array}$ \\
\hline $\mathrm{P} 2$ & \begin{tabular}{|l|} 
A speaking \\
platform on the \\
net for \\
individuals, \\
groups and \\
organizations, real \\
time and \\
interaction \\
features \\
\end{tabular} & \begin{tabular}{|l|} 
Advantages: not too \\
many hardware and \\
software requirements \\
Disadvantages: \\
non-instinctive types \\
of editions, change \\
problems among \\
different systems
\end{tabular} & $\begin{array}{l}\text { Interface, new tools, } \\
\text { system, drawing diary } \\
\text { system (inspiration: } \\
\text { chart by Apple Daily), } \\
\text { a video of "Who } \\
\text { comes to my house?" }\end{array}$ & $\begin{array}{l}\text { Blogs can } \\
\text { provide } \\
\text { features, } \\
\text { contents, } \\
\text { sharing and } \\
\text { entertainment. }\end{array}$ & $\begin{array}{l}\text { Keep a diary with voice, } \\
\text { keep a diary with video, } \\
\text { more lively editions, interface similar to } \\
\text { second life, addition of situations }\end{array}$ \\
\hline $\mathrm{P} 3$ & $\begin{array}{l}\text { Blog: easy, public, } \\
\text { only a browser } \\
\text { and online } \\
\text { features required, } \\
\text { limited hardware } \\
\text { and software } \\
\text { demands }\end{array}$ & \begin{tabular}{|l|} 
Advantages: \\
convenience-built-in \\
picture and \\
description features \\
Disadvantages: \\
various editions \\
(different interfaces \\
for the same \\
platform)
\end{tabular} & $\begin{array}{l}\text { Basic } \\
\text { requirements - photos, } \\
\text { blogs, videos are } \\
\text { sufficient, minor } \\
\text { software for future } \\
\text { demands, ex: } \\
\text { (1) drawing (painter); } \\
\text { and (2) real time video } \\
\text { communication } \\
\end{array}$ & $\begin{array}{l}\text { Business } \\
\text { values, future } \\
\text { features of blog } \\
\\
\end{array}$ & $\begin{array}{l}\text { (1) Broadcasting station (personal) } \\
\text { (2) 3D, simulation of city-situational } \\
\text { (3) Playful, ex: Blog e-pet can have } \\
\text { features of doing a job and sending } \\
\text { flowers, etc. } \\
\text { (4) Gift giving: "My Treasure Box" can } \\
\text { collect and display virtual treasures. } \\
\text { (5) Professional (featured games), } \\
\text { general (easy), ex: a burning software }\end{array}$ \\
\hline $\mathrm{P} 4$ & \begin{tabular}{|l|} 
Share photos, \\
diaries and \\
favorite messages, \\
express yourself \\
and make friends \\
with others
\end{tabular} & $\begin{array}{l}\text { Convenient, } \\
\text { interesting, may do } \\
\text { whatever you like, } \\
\text { incompatibility } \\
\text { among platforms }\end{array}$ & $\begin{array}{l}\text { New features required, } \\
\text { Painter will help } \\
\text { addition of non-text } \\
\text { images, applicable } \\
\text { software may be } \\
\text { added, ex: animation, } \\
\text { video, real time } \\
\text { communication }\end{array}$ & \begin{tabular}{|l|} 
Features, web \\
sites, \\
impressions, \\
communication, \\
contents, and \\
sharing of blogs
\end{tabular} & $\begin{array}{l}\text { Record your day with voice, converted to } \\
\text { 3D, flash, changeable 3D settings, } \\
\text { addition of situations }\end{array}$ \\
\hline
\end{tabular}

\section{Discussion}

Blog design issues were used to explore if schema changes helped interface design on an early stage in this research. Schema results analyzed in the first phase were served as the parameters of the experiment. The second phase, all participants have design experience. Both of them are students of digital media design department and the other two are from the visual communication design department. All four attended the brainstorming 
meetings and discussed how to design blogs freely. The same participants took part in this two-section experiment. Dependent samples were taken for an understanding of a causal relationship between these two parts. The experiment consists of the experimental group and the control group. The former did not refer to the comparison table of schema changes for users at three points of time, but the latter did.

The result indicates the experimental group of the first part did not have particular issues for discussion and a conclusion reached was they expected to have features of animation, a video system, real time communication, a drawing diary system, and drawing. These demands were more conservative and could be satisfied by present software. In the beginning, the control group of the second part experiment did not consider the data provided useful; however, four participants discovered the data revealed users' and suppliers' positions after in-depth discussion and future functions and business values of blogs were located. Then, viewpoints of users and suppliers were discussed. They were totally involved and personal experience (e.g., blog + games), interests, situational awareness, and future design (imagination of future life) were integrated for the final draft. Innovative ideas totally different from the result in the first part experiment were obtained. This two-part experiment provides evidence that useful information offered in the blog design brainstorming meeting on an early stage results in new and interactive concepts for blog design. The results are summarized as follows: (1) new interactive ideas of integrating voice, pet keeping and games for future blog development; (2) integration of current applicable multimedia skills and games; (3) diary and sharing features $\longrightarrow$ video feature $\longrightarrow 3 \mathrm{D}$ virtual world (ambient experience) with basic and professional advanced features; (4) applying product placement to merchandise to create business opportunities for infinite and interesting advertisements; (5) futuristic shopping pattern — individual blog virtual world and more convenient; and (6) Blog may become a second life of an individual.

It is thus expected blog design may develop in the direction of providing better business service, a situational awareness shopping, user-centered design, and new interactive concept (see Figure 5).

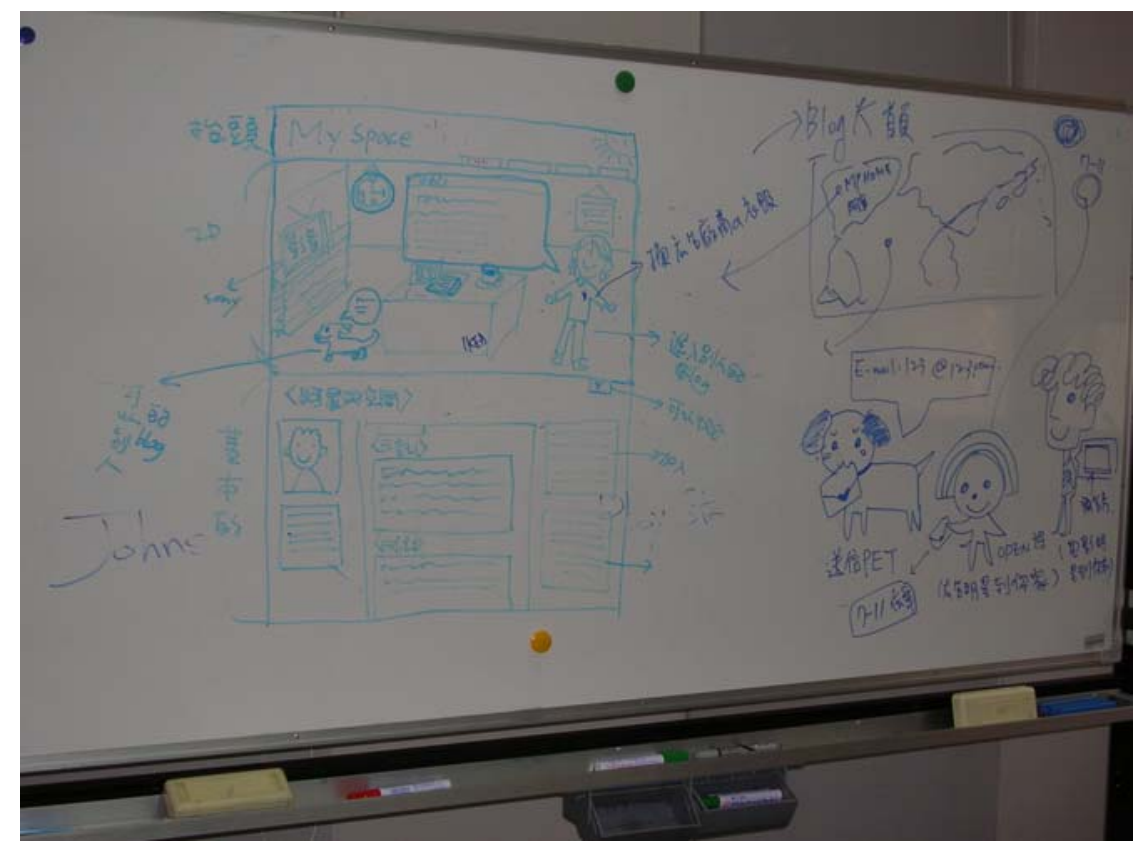

Figure 5. Final blog design sketch discussed by four participants on the whiteboard (a co-designed blog). 


\section{Conclusions}

The purpose of this research is to verify the tests that potential customer needs and innovative ideas can be located more easily by referring to the comparison table of schema changes for users at three points of time. The result obviously reveals that the control group got better innovative ideas after referring to the comparison table and discussing. Viewpoints of the research are summarized as follows:

(1) Four participants incorporate or absorb external things through assimilation and accommodation at the brainstorming meeting causing schema changes in two experiment parts (refer to Table 3).

(2) Four participants who attended the brainstorming meeting for empathic design have experience of maintaining a blog for three to five years and design for one to three years. Affected by user experience, they have a common experience of blog use and try to bring their design creativity into full play. Thus, a common consensus was reached easily.

(3) A series of experimental interactions like influence of experience indicate the importance of blog management and game experience manifested by imaginations of the future life and entertainment of situational awareness.

(4) There are interactive interface for ideal blog design was presented (an innovative design was presented).

\section{References}

Adams, M. J., \& Collins, A. (1979). A schematheoretic view of reading. Norwood: Ablex.

Chang, H. W., Hsu, C. H., Cheng, H. W., Lei, K. L., \& Ksuo, C. H. (2004). Developmental psychology. Taipei: National Open University.

Chen, L. C. (1992). Cognitive development and guidance. Taipei: Psychological.

Chou, W. C. (2002). Research method-Empirical study approach. Taipei: Psychological.

Dorothy, L., \& Jeffrey, F. R. (1997). Spark innovation through empathic design. Harvard Business Review, 75(6), 104.

Fiske, S. T., \& Taylor, S. (1991). Social cognition (2nd ed.). New York: Don McGraw-Hill.

Kuniavsky, M. (2003). User expectations in a world of smart devices (Online PDF). Retrieved from http://www.adaptivepath.com/ideas/essays/archives/000272.php

Moates, D. R., \& Schumacher, G. M. (1980). An introduction to cognitive psychology. Belmont: Wadsworth.

Norman, D. A. (1999). Invisible computer: Why good products can fail, the personal computer is so complex and information appliances are the solution. Cambridge: MIT Press.

Paluch, K. (2006). What is user experience design. Retrieved from http://www.montparnas.com/articles/what-is-user-experience-design/

Piaget, J. (1954). The construction of reality in the child. New York: Basic Books.

Reiss, E. (2009). A definition of "user experience". Retrieved from http://www.fatdux.com/blog/2009/01/10/a-definition-of-user-experience/

Rifykin, J. (2001). The age of access: The new culture of hypercapitalism, where all of life is a paid-for experience. (Y. H. Huang \& Y. Liou, Trans.). Taipei: Yuan-Liou Publishing Co., Ltd..

Rubinoff, R. (2004). How to quantify the user experience. Retrieved from http://www.sitepoint.com/article/quantify-user-experience/

Su, C. W., Cheng, H. W., Ke, H. W., Lin, M. C., Wu, M. E., Hsing, M. L., Chen, L. C., Lin, H. Y., \& Chen, S. M. (1995). Developmental psychology. Taipei: Psychological.

Wang, S. H., Chuang, T. L., Fang, K. T., \& Ho, M. C. (2008, December). Exploring schema changes for design blog. Journal of Science and Technology (Humanities \& Sociology), 17(3), 197-208. 